\title{
The Mediating Role of Charismatic Leadership Communication in a Crisis: A Malaysian Example
}

International Journal of Business Communication

I-25

(C) 2015 by the Association for Business Communication Reprints and permissions: sagepub.com/journalsPermissions.nav DOI: I0.1 I77/23294884|5572782 jbc.sagepub.com

(SAGE

\section{Jamilah Jamal' and Hassan Abu Bakar'}

\begin{abstract}
This study develops a model to advance research on public organization reputation by integrating crisis responsibility with charismatic leadership communication. Based on situational crisis communication theory, the model was tested using structural equation modeling with data obtained from a sample of 383 employees of public organizations in Malaysia. The mediation model indicated that the dynamic mechanism of charismatic leadership communication partially mediated the relationship between crisis responsibility and perceived organizational reputation during a crisis. These findings validated the proposed model and, in particular, confirmed empirically the central role of charismatic leadership communication processes in organization. This study provides insights into the role of charismatic leadership communication in the organizational reputation processes. The model established can serve as an instructive guide for both organization and corporate leaders in managing a crisis and reputation. A practical implication of the findings is that, during a crisis, a crisis leader should engage in charismatic leadership communication effectively to mitigate the crisis impact and strengthen organizational reputation. More important, the findings indicate that charismatic leadership communication contributed to organizational reputation explicitly brought charismatic leadership communication to the forefront of organizational reputation management.
\end{abstract}

\section{Keywords}

crisis responsibility, charismatic leadership communication, perceived organizational reputation, situational crisis communication theory

\footnotetext{
'Universiti Utara Malaysia, Sintok, Kedah, Malaysia
}

\section{Corresponding Author:}

Jamilah Jamal, Communication Department, School of Multimedia Technology and Communication, College of Arts \& Sciences, Universiti Utara Malaysia, 06010 Sintok, Kedah, Malaysia.

Email: jamilah@uum.edu.my 
For today's increasingly complex organizations, scholars have dedicated their attention to public organization reputation focusing on issues such as political legitimacy (Vigoda-Gadot, Zalmanovitch, \& Belonogov, 2012), managerialism and corporate governance (Wæraas \& Byrkjeflot, 2012), organizational performance (O'Toole \& Meier, 2009), ethics and compliance (Lager, 2010), public complaints crises (Grunwald \& Hempelmann, 2010), and government communication (Liu, Horsley, \& Yang, 2012). With greater frequency of crisis occurring across specialized public organizations, communication scholars have focused on the issues concerning the problems of reputation management that threaten a public organization's reputation. However, current explanatory theories and perspectives toward crisis and reputation management require expansion and modification to better capture the increasing complexities in public organizations especially about the role of leadership during crisis and its effects on organizational outcomes. Organizational leaders can affect the dynamics of organization reputation in a crisis through their charismatic leadership. This research seeks to fill the lacuna in existing studies by more comprehensively investigating and understanding the dynamics of one core aspect of organizational reputation - that of charismatic leadership communication during a crisis in public organizations.

Previous research has indicated that communication plays a major role in constructing and protecting government bodies' reputation (Liu et al., 2012) and helping to form the perceptions of multiple stakeholders of their bodies' reputation especially in crises situations (Maor, Gilad, \& Ben-Nun Bloom, 2013). However, to date, research has yet to draw conclusions about the role of leadership communication in mitigating the impact of a crisis on reputation as seen through the lenses of internal stakeholders. As the internal stakeholders, employees are recognized as the human capital that is regarded as the most valuable asset of the organization. Thus, avoiding a dramatic downturn is essential especially among the talented young people by having a stable, strong, and favorable organizational reputation. Following this line of reasoning, this article will focus on the perceptions of the employees in the selected public organizations in Malaysia on crisis responsibility and organizational reputation by considering the role of charismatic leadership communication in managing crises. The findings of this study are important because they reflect employee assessments and evaluations of crisis and reputation management in Malaysia. In addition, assessing the importance of the role of communication during a crisis among public sectors' employees is scarcely being investigated.

This research directly contributes to the business communication (and specifically public relations) literature in several ways. First, this research incorporates an in-depth analysis of leadership communication in public organization. As Watson (2007) and Kakavogianni (2009) stated, the current literature has not yet analyzed fully the potential charismatic communication aspects of a leader by considering the dynamic interplay of leadership, communication, and employees' perceptions of organizational reputation during a crisis.

Second, most crisis and organization reputation research has been conducted in North America, Europe, and, to some degree, China (PRC), and Taiwan. To extend, broaden, and complement this work, this study considers the mediating effects 
of charismatic leadership communication on the relationship between organizational crisis and organizational reputation in the vastly understudied (and inherently ethnically diverse) Southeast Asian country of Malaysia. We strongly contend that broadening the literature via Asian-based studies such as this one are essential as we move toward more meaningful and deeply thought through comparisons and contrasts between people from nations located in various regions (see also Ota, McCann, \& Honeycutt, 2012). In the few studies having non-Western samples, however, communication remains absent from the study of the organizational reputation (Abd-ElSalam, Shawky, El-Nahas, \& Nawar, 2013; Hamdi \& Rajablu, 2012). Thus, we test our communication-centered model using members of public organizations in Malaysia. This line of research answers Seibold, Hollingshead, and Yoon's (2014) call to identify the underlying communication process variables linking organizational traits and behavior and important work group outcomes in a different setting. More specifically, this research accepts Jin \& Yeo (2011) invite to further investigate the effect of leadership communication in a reputation and relationship-building process in crisis situations.

This article comprises three major sections. The first discusses recent advances in the study of organizational crisis and public organization reputation management, provides a theoretical elaboration of leadership communication during crisis and a detailed discussion of the derived research hypotheses. The second section describes methods employed in this study and subsequently presents the results. The final section provides discussion, research limitations and implications as well as future recommendations.

\section{Review of Literature}

\section{Organizational Crisis}

A review on scholars' definition of organizational crisis shows some commonalities, including the fact that a crisis: (1) is an unplanned event that has the potential to dismantle the entire structure of an organization, (2) can affect the organization's internal and external stakeholders, (3) may occur in any organization across all industries nationwide, and (4) may affect the survival of an organization (King, 2002). This study adopts Coombs and Holladay's (2010) definition of an organizational crisis as "the perception of an unpredictable event that threatens important expectancies of stakeholders and can seriously impact an organization performance and generate negative outcomes" (p. 238). In this study, crisis management is "a set of factors designed to combat crises and to lessen the actual damage inflicted" (Coombs \& Holladay, 2010, p. 238) while crisis management team refers to a group designated by the organization to be responsible for the crisis management plan and to execute the plan when the need arises. The team members of the crisis management plan were selected by the top management based on specific criteria such as expertise in own field and experience in handling a crisis and were chosen to represent various departments in the organization. 


\section{Crisis Responsibility}

Crisis responsibility refers to the degree to which stakeholders attribute responsibility for a crisis to an organization (Coombs, 2007). Situational crisis communication theory (SCCT) categorized types of crisis into three crisis clusters, namely (1) the victim cluster, (2) the accidental cluster, and (3) the preventable cluster. Each cluster explains a different level of crisis responsibility attributed to the organization. The victim cluster is linked with a weak degree of responsibility, while the accidental cluster is associated with a reasonable degree of responsibility, and the preventable cluster is associated with a high level of responsibility to the organization. A preventable crisis is associated with a strong attribution of crisis responsibility that could affect reputation severely (Coombs \& Holladay, 2010). Thus, crisis responsibility is related inversely to organizational reputation; the higher the level of crisis responsibility held by the organization the more severe the potential impact to its reputation.

\section{Organizational Reputation}

Among the many definitions of organization reputation academics have proposed, scholars have agreed that the most precise and widely accepted is that of Fombrun (1996) who defined corporate reputation as “a perpetual representation of a company's past actions and future prospects that describes the firm's overall appeal to its key constituents when compared with other leading rivals" (p. 72). Various definitions of corporate reputation have reflected the organization's ability to fulfill its stakeholders' expectations (Delgado-Garcia, De Quevedo-Puente, \& De La Fuente-Sabate, 2010). In the present study, corporate reputation is conceptualized as the perception of an organization based on its internal stakeholders' (employees) interpretations of that organization's past, present, and future activities and the way in which these are communicated (Tucker \& Melewar, 2005). This definition is drawn from inferences about employees' perceptions of organizational reputation based on their experiences being a member of the organization. As part of the organization, the interpretation these employees made was crafted through their interactions with the organization. Organization reputation in this study was measured using the reputation quotient developed by Fombrun and Van Riel (2004). The reputation quotient assesses employees' perceptions toward their organization based on six attributions, namely, vision and leadership, social and environmental responsibility, emotional appeal, products and services, workplace environment, and financial performance.

The previous studies indicated differences between Eastern and Western perspectives in the way in which organizational reputation was perceived (Chetthamrongchai, 2010). Chetthamrongchai (2010) found that while Asian executives perceived reputation as being more associated with tangible benefits such as better financial performance and developing strategic partnerships, the North American and European executive saw organizational reputation as being more associated with intangible benefits such as recruitment and retention of human capital, gaining public support and trust and, building policy initiatives. These differences may help to explain the way in 
which Malaysian employees perceive their organizational reputation and leadership communication.

\section{Charismatic Leadership and Communication}

Charismatic leadership communication in this study is conceptualized as "a distinctive set of leader's interpersonal communicative behaviors geared toward the optimization of hierarchical relationships" (de Vries, Bakker-Pieper, \& Oostenveld, 2010, p. 368) in order to form a favorable perception. Unlike other leadership practice definitions that focused on the managerial aspect and styles of leadership, this comprehensive definition suggests that leaders must employ more interpersonal communication skills in achieving the organization's goal. This does mean that a leader should depend on interpersonal skills exclusively, but should see these skills as complementary. We argue that adopting this set of interpersonal communicative behaviors will enhance leaders' ability to manage a crisis thus creating better perceptions of organizational reputation.

Because of the political nature of public organization, leaders in public organization are often perceived as highly effective when they demonstrate verbal intelligence or oratorical attributes such as effective interpersonal skills (Levine, Muenchen, \& Brooks, 2010; Renshon, 1995). Bligh, Kohles, and Meindl (2004) argued that attributes of interpersonal skills are strongly demonstrated by leaders when a crisis involved national or political issues that required influencing public perceptions. Thus, in the present study, leadership communication will be examined from an interpersonal aspect including the demonstration of communication behaviors a charismatic leader exhibits. The communications behaviors such as expressing appropriate emotions by leaders show the degree of their involvement with the subject matters.

Scholars have agreed that charisma can be taught (Antonakis, Fenley, \& Liechti, 2011). Traits that are not inborn, such as physical appearance and interpersonal skills, can be acquired through learning to complement the inborn traits such as physical unattractiveness. Ultimately charisma is the result of excellent communication and interpersonal skills, and these skills can be learned and developed. Charismatic gap can be bridged through training which will significantly improve a leader's performance. Scholars also suggested that charisma can be acquired by bolstering one's ability to gain and maintain other people's attention to his or her ideas (Conger, Kanungo, \& Menon, 2000). This way, charismatic leader will be able to successfully communicate ideas and processes.

Charismatic leadership communication exhibited by leaders is closely associated with the leader's ability to practice the traits of a competent communicator and demonstrate authenticity and trust to deal with crisis (Schoenborn, 2005). At this stage, an authentic leader is expected to communicate the realities and possibilities to gain stakeholders trust and confidence. This is done through his or her ability to develop a level of trust and demonstrate authenticity in order to influence or motivate an organization's stakeholders toward a specific behavior or belief initially set by the organization. This ability is not always an inborn trait but rather can be gained through training 
(Levine et al., 2010). Wang and Hsieh (2013) suggested that leadership derives from one's life experiences, which provide advantages for exercising authentic morality and integrity (George, Sims, McLean, \& Mayer, 2007). Frese, Beimel, and Schoenborn (2003) suggested that training for charismatic communication emphasizes both content (stressing the importance of the project, by sharing a vision related to the project, by increasing the confidence of the subordinates, and by stressing a common goal) and stylistic components such as nonverbal communication including power, confidence, and a dynamic presence. Most organizations emphasize training for leaders to "bring out" or to polish the charismatic communication in them (Hooijberg \& Choi, 2001).

Crisis management is a challenge for leadership as it tests the quality and character of leaders, including their communication skills. In view of this, scholars in public relations have highlighted the importance of analyzing leadership traits and the qualities of leaders in an organizational crisis context (Meng \& Berger 2013; Schoenberg, 2005). In addition, current research in public relations and strategic communication has recognized the importance of applying leadership communication to develop successful communication leaders in the institutional context (Meng \& Berger, 2013).

\section{The Situational Crisis Communication Theory}

The SCCT was developed to guide leaders to make decisions on which to create response strategy to employ in specific crisis situations to mitigate threats to its reputation (Claeys, Cauberghe, \& Vyncke, 2010; Coombs, 2004, 2007). The SCCT evolved from a number of studies that examined how a crisis might shape the selection of crisis response strategies and/or that examined the effect of crisis response strategies on organizational reputation. The idea was to articulate a theory-based system for matching crisis response strategies to the crisis situation to best preserve organizational reputation. The SCCT focuses on the use of communication to preserve and protect an organization's valuable reputation (Coombs, 2007). It argues that, as the reputational threat increases, crisis managers should use response strategies that demonstrate a higher level of acceptance of responsibility for the crisis and address the organization's concerns for the victims involved.

The notion of selective retention based on specific crisis situations suggests that, as organizational reputational threat increases, crisis managers should use response strategies demonstrating a higher level of acceptance of responsibility for the crisis and addressing organizational concerns, especially those of the organizational stakeholders involved. Thus, a manager's actions toward a crisis reinforce those existing attitudes and beliefs of stakeholders toward the organization (Claeys et al., 2010; Coombs, 2004, 2007). Applied to SCCT, positive perceptions of charismatic leaders' communication indicating leaders are competent, confident, enthusiastic, and skilled also would influence positively employee perceptions of organizational reputation. It seems reasonable then, that leader communication during crisis as a process could strengthen organizational reputation. 


\section{Hypothesis Development}

Based on the SCCT discussed above, this study proposes a theoretical framework derived from the literature in crisis communication and leadership management. Four hypotheses developed from the proposed theoretical framework are discussed in the following section.

\section{Crisis Responsibility and Perceived Organizational Reputation}

Crisis management literature suggests that crisis responsibility directly affects organizational reputation (Coombs, 2007, 2012). Stakeholders make attributions of crisis responsibility based on the cause triggering the crisis (Wester, 2009). In addition, initial crisis responsibility reflects the degree to which stakeholders believe organizational actions have triggered the crisis (Weber, Erickson, \& Stone, 2011). Previous study on crisis management has demonstrated that attribution of crisis responsibility is related negatively to favorable organizational reputation (Coombs, 2004, 2007; Coombs \& Holladay, 2002); the more the organization is perceived as responsible for the crisis, the more severe the damage to its reputation (Sisco, 2012). However, Helm and Tolsdorf's (2009) recent findings suggested that organizational reputation has the potential to reduce the negative effects posed by a crisis threat. They further concluded that the effect of the crisis is weak when the reputation is good and strong when the reputation is bad.

An organization's actions either to assume or to reject crisis responsibility are crucial in rebuilding a reputation damaged by a crisis threat thus confirming the direct link that exists (Coombs, 2007; Coombs \& Holladay, 2006). In the event the organization is perceived as responsible for a crisis, the acceptance of crisis responsibility will result in a positive reputation. Therefore, the following hypothesis is advanced for testing:

Hypothesis 1: Attribution of crisis responsibility is related to perceived organization reputation.

\section{Crisis Responsibility and Charismatic Leadership Communication}

Empirical research has suggested that the role of crisis communication is one influential factor in the attribution of charismatic leadership (Halverson, Holladay, Kazama, \& Quiñones, 2004). In addition, previous study has demonstrated a positive link between leaders' charismatic communications and perceptions of leadership effectiveness after the crisis has hit. In another study, crisis responsibility perceptions were found to be related to expected leadership effectiveness while higher charismatic delivery in communication was linked positively with higher ratings of charisma and effectiveness (Bligh, Kohles, \& Pillai, 2005).

Charismatic leadership communication was most likely to emerge when crises involved national or political issues, including national security, which placed great 
responsibility on the government's side. Bligh et al. (2005) found that the context of a national crisis directly affected the leader's charismatic leadership communications reflecting a great sense of responsibility for the country's vulnerability on national security. In addition, increased perception of charismatic leadership communication is associated with increased ratings of charisma and effectiveness in overcoming crises. The influence of a crisis on a leader's use of charismatic rhetoric indicated a strong, positive relationship between leader charismatic rhetoric and perceptions of leader effectiveness in managing that crisis (Davis, 2012). We argue that the more the attribution of crisis responsibility is associated with the organization, the higher charismatic leadership communication is demonstrated by the organization. Therefore, the following hypothesis is advanced for testing:

Hypothesis 2: Attribution of crisis responsibility is related positively to the demonstration of leader's charismatic leadership communication.

\section{Charismatic Leadership Communication and Perceived Organizational Reputation}

Drawing on charismatic leadership communication in a situational context, previous study has indicated that leaders' behavioral charisma affect organization reputation significantly (Madlock, 2008; Pillai, 1996). For example, Walter and Bruch (2009) identified charismatic leadership behavior as one significant contextual antecedent of organization reputation during crisis. Empirical research has also demonstrated that leaders' unfavorable communication behaviors lead to negative outcomes when the crisis was mismanaged, thus burdening organization with bad reputation (Coombs, 2007; Pillai \& Meindl, 1998).

Managing reputation is an important part of leadership which helps determine organizational success (Van der Jagt, 2005). Recently, research also has confirmed that a leader's visibility and immediate response to a crisis influences stakeholders' perceptions toward organizational reputation after the crisis (Turk, Jin, Stewart, Kim, \& Hipple, 2012). We argue that the conclusion might vary according to the degree of demonstration of a leader's charismatic communication in his or her response throughout the crisis period. A lack of charismatic communication and the ability to immediately respond to crisis are critical factors affecting organizational reputation.

Crisis leadership literature suggests that a leader should assume the role of being the organization's spokesperson during a crisis (Littlefield \& Quennette, 2007; Lucero, Tan, \& Pang, 2009) to mitigate unfavorable impacts; thus, a leader must not only be visible during a crisis but also demonstrate these leadership communication attributes while assuming the spokesperson's role for the organization. We argue that a leader's inability to employ charismatic leadership communication eventually will affect a leader's efforts to change crisis outcomes and rebuild tarnished reputations. Thus, we advance the following hypothesis:

Hypothesis 3: Leader's demonstration of charismatic leadership communication is related positively to perceived organizational reputation. 


\section{The Mediating Roles of Charismatic Leadership Communication}

Charismatic leadership communication is more crucial during the response stage of the crisis than in the prevention and recovery stages (Hale, Dulek, \& Hale, 2005). Based on the attribution of crisis responsibility, an organization in crisis experiences communication challenges deciding on the response and in what manner the communication should be employed to mitigate the effects of the crisis. Appropriate responses taken by responsible leadership after the crisis reduce the effects of reputation instabilities (Coldwell, Joosub, \& Papageorgiou, 2012). In addition, Coldwell et al. (2012) suggested that inappropriate leader response might affect adversely organizational reputation.

During a crisis, responsive leaders focus on reestablishing the relationships between the organization and stakeholders and strive for a positive crisis outcome (Kakavogianni, 2009), especially when the organization is perceived as being responsible for triggering the crisis (Coombs, 2007). Thus, in times of crisis, a leader's responsibility is to ensure that the organization communicates promptly, responsibly, and effectively. More precisely, scholars suggested that, when stakeholders attribute crisis responsibility to the organization, a successful leader will (and should) appropriately and charismatically manage that crisis and lead through communication.

Related to crisis responsibility and organizational reputation and, aligned with the role of communication as posited in the SCCT, we argue that charismatic leadership communication performs a substantial function with respect to a crisis threat. The SCCT posits that, as the crisis team adjusts to the initial reputational threat, leaders are held responsible for altering the perceptions of their stakeholders about the potential impact of the crisis. Thus, we argue that perceived positive charismatic leaders' communication indicating that leaders are competent, confident, enthusiastic, and skilled will influence positively the employee's perception of organizational reputation. Therefore, the following hypothesis is advanced for testing:

Hypothesis 4: Leader's demonstration of charismatic leadership communication during crisis mediates the relationship between crisis responsibility and perceived organizational reputation.

\section{Method}

\section{Participants}

The participants of this study were public organization officers from selected public organizations in Malaysia. These organizations were chosen because they were directly affected by the crisis and also involved in managing it. The participants were of lower and middle managerial levels and from various departments and across job functions who were selected based on random sampling method. To ensure participants have sufficient knowledge and understanding about crisis, leadership, and organization reputation, the requirements were that they (1) must be familiar with the organization (a minimum of 6 to 9 months' working experience) and (b) must have had at least 
indirect experience in assisting the implementation of crisis management even though they were not on the crisis management team. In addition, all participants possessed a bachelor's degree as a minimum educational qualification to qualify for this survey.

Consistent with the minimum time period typically needed to develop a mature workplace relationship (Graen \& Uhl-Bien, 1995), our sample excluded employees who had been in their organization for less than 3 months (Bakar, Dilbeck, \& McCroskey, 2010; Bakar \& Sheer, 2013; Graen \& Uhl-Bien, 1995). Hence, we ensured that the participants were sufficiently familiar with their leaders so that we could get a more accurate evaluation of their leaders' charismatic leadership communication.

In that employee sample, $54.8 \%$ were male and $45.2 \%$ female; $73 \%$ were ethnically Malay, $21 \%$ Chinese, and $6 \%$ Indians. Approximately $63 \%$ of the participants were lower and middle-level managers and 37\% were top-level managers. Seventy-one percent of the respondents had been working for 1 to 10 years in the organization; $29 \%$ indicated that they had worked more than 10 years for the organization. Eighty-three percent had been reporting to the present manager for 1 to 5 years while $17 \%$ had been reporting to the current manager for more than 5 years.

\section{Procedure}

Participants of this study responded to survey questions regarding crisis responsibility, charismatic leadership communication, and perceived organization reputation. In measuring crisis responsibility, participants are given the scenario of the crisis to enable them to recall the crisis. Then, respondents were asked to make attribution of the crisis responsibility based on the given crisis scenario. The questionnaire assessed participants' perceptions of the (a) cause of the crisis, whether it is caused by the organization or circumstances, (b) organization's ability to control or to avoid the crisis, and (c) organization's ability to manage the crisis.

In the second section of the survey, the respondents were asked to answer questions regarding their perceptions of organization reputation. Participants' perceptions toward their organization were assessed based on reputation quotient's six attributions, namely, vision and leadership, social and environmental responsibility, emotional appeal, products and services, workplace environment, and financial performance. As for charismatic leadership communication, participants were asked to recall and evaluate their leaders' charismatic leadership communication aspects while managing the crisis. The aspects measured in the survey were the leaders' task-oriented communication, emphatic, and enthusiastic traits.

Survey packs were sent to respondents via the human resources department of each participating organization. Prior to the survey, participants were identified based on a complete list of employees who are familiar or have experience with crisis given by the human resources department of each participating organization. A cover letter outlined the research process, solicited voluntary participation, and assured confidentiality. The survey pack contained questionnaires and preaddressed envelopes for participants to return the completed questionnaires directly. Of the 1,200 questionnaires sent to senior and middle managers, 383 were returned, a $32 \%$ response rate. 


\section{Framing of the Contextual Crisis}

For the purpose of measuring crisis responsibility and organization reputation, an actual crisis scenario was chosen to frame the contextual situation for this study. A government agency was investigating an allegation of corruption involving a member of the state executive. This investigation has led to the death of the state executive's political secretary while under the custody of the agency (The Star, July 22, 2009; The New Straits Times, July 18, 2009). This incident had triggered media's closed scrutiny on the crisis, including mainstream and alternative media and bloggers questioning the reputation of the government bodies involved in managing the inquest (Hector, 2011; Reduan, 2014). The investigation of this case is still ongoing, resulting in a prolonged political controversy involving a regulatory body (Tan, 2014). This incident is categorized under preventable crisis, which leads to a maximum impact on reputation (Coombs, 2010, Coombs \& Holladay, 2006), if the government is proven as responsible for the crisis.

The criteria for selecting the crises were (1) generalizability - all government organizations are likely to have same impact, or to certain degree, be affected by the crises; (2) recent - all crises are either recent and/or, ongoing; (3) familiar crises - which public are aware of, involved with, or directly affected by the crises; and (4) all the three crises are interrelated and of the same criteria, which fall under the category of preventable crisis. These criteria are (1) organization investigation/action that resulted in the death of nonemployee, which led to; (2) intense scrutiny from news media, as a result; and (2) government organizations are caught/put/being at the center of a political controversy. In this study, participants made the attribution of crisis responsibility based on the selected crises framing given and evaluated their leaders' charismatic communication demonstrated while managing the crises.

The leaders in this study were from the federal government departments and were among the highest level leaders not politically appointed. They work directly under the ministries and were government appointed. These leaders are part of the civil service system and experience significant pressures from powerful outside forces such as public interest groups and legislators.

\section{Instrumentation}

An English-language version of organizational crisis, perceived reputation, and charismatic leadership communication questions was used in the instrument developed for this study. This was in accordance with other researchers' use of language preference when studying Malaysian subjects (Bakar et al., 2010) because working-class Malaysians are considered sufficiently proficient in the English language. Details of the instruments used in this study are as follows.

Organizational Crisis Responsibility. The perception of organizational crisis responsibility was measured with a scale developed by Coombs and Holladay (2002). In the present study, the 8-item Likert-type scale generated a Cronbach's alpha of .76. 
Table I. Means, Standard Deviations, and Intercorrelations Among the Variables.

\begin{tabular}{lllllll}
\hline Variables & $M$ & $S D$ & 1 & 2 & 3 \\
\hline I. Crisis responsibility (CRISIS) & 3.42 & 0.65 & - & & \\
2. Perception of organizational reputation & 4.1 & 0.59 & $.23^{*}$ & - & \\
$\begin{array}{l}\text { (REPUTATION) } \\
\text { 3. Charismatic leadership communication (CHARISMA) }\end{array}$ & 3.9 & 0.62 & $.25^{*}$ & $.54^{*}$ & - \\
\hline
\end{tabular}

$*_{p}<.01$.

Perceived Organization Reputation. Participants' perceived organizational reputation was measured with a 20-item Likert type scale developed by Fombrun and Van Riel (2004) with adjustment made to suit public organization. In the present study, the revised 16-item Likert-type scale generated a Cronbach's alpha of .95.

Charismatic Leadership Communication. The charismatic leadership communication was measured with a scale developed by Levine et al. (2010). In this study, the 23-item scale generated a Cronbach's alpha of .97 . Because previous study produced mixed results on this measurement scale, confirmatory factor analysis (CFA) was performed to determine the factors. The result shows that 23 items loaded significantly in three dimensions, namely, task-oriented communication (TOC), enthusiasm (ENT) and empathy (EMP). The CFA result produces an acceptable fit for this model with $\chi^{2}=$ $720.325, p>.01 d f=227$; comparative fit index $(\mathrm{CFI})=.94$; normed fit index $(\mathrm{NFI})=$ .91 ; standardized root mean square residual $(\mathrm{SRMSR})=.027$; and root mean square of approximation $($ RMSEA $)=.07$. Average variance extracted for the three dimensions was $\beta=.70, .61$, and .70 , respectively. The composite reliability for ENT was .94, TOC was .95, and EMP was .92. Thus, it can be concluded that the Charismatic Leadership Communication Scale is a valid and reliable instrument to measure the construct of charismatic leadership communication.

\section{Data Analysis}

Prior to conducting hypothesis testing, we tested the data for entry errors and normality (based on kurtosis and skewedness) of the distribution of each item and the composite score of each variable. The majority of the items appeared within normal ranges. Descriptive statistics and correlations for all variables are reported in Table 1.

\section{Confirmatory Factor Analysis}

We conducted a confirmatory factor analysis (CFA) to determine the distinctiveness of the three variables: (1) crisis responsibility, (2) employees' perceptions of organizational reputation, and (3) charismatic leadership communication. A hypothesized threefactor structure with distinct, correlated factors for crisis responsibility, employees' 
Table 2. Confirmatory Factor Analysis of the Structure of the Measured Variables.

\begin{tabular}{lcccccc}
\hline & & & & \multicolumn{3}{c}{ Discriminant validity } \\
\cline { 5 - 7 } & Cronbach's $\alpha$ & CR & AVE & CR & CLC & POR \\
\hline CRISIS & .76 & 0.805 & 0.514 & 0.717 & & \\
CHARISMA & .97 & 0.968 & 0.909 & 0.233 & 0.953 & \\
REPUTATION & .95 & 0.969 & 0.863 & 0.250 & 0.569 & 0.929 \\
\hline
\end{tabular}

Note. AVE, average variance extracted; CRISIS = crisis responsibility; REPUTATION = employees' perceptions of organizational reputation; CHARISMA = charismatic leadership communication.

Table 3. Confirmatory Factor Analysis of the Structure of the Measured Variables.

\begin{tabular}{lcccccc}
\hline Model & $\chi^{2}(d f)$ & $\Delta \chi^{2}(d f)$ & CFI & NFI & SRMSR & RMSEA \\
\hline Three-factor & $208.70(42)$ & - & .97 & .90 & .04 & .05 \\
Two-factor & $225.74(40)$ & $1004.41(3)$ & .90 & .92 & .03 & .21 \\
One-factor & $307.73(41)$ & $237.04(4)$ & .89 & .87 & .10 & .20 \\
\hline
\end{tabular}

Note. $\mathrm{NFI}=$ normed fit index; $\mathrm{CFI}=$ comparative fit index; SRMSR = standardized root mean square residual; RMSEA = root mean square error of approximation. All $\chi^{2}$ and $\Delta \chi^{2}$ values are significant at $p<.01$.

perceptions of organizational reputation, and charismatic leadership communication was compared with a series of possible models: (1) a two-factor model, in which the items of crisis responsibility, employees' perceptions of organizational reputation, and charismatic leadership communication were loaded on a common factor; (2) a onefactor model, in which all items were loaded on one factor. Details of Cronbach's alpha, average variance extracted, and composite reliability for each construct are presented in Table 2.

The results of the CFA, shown in Table 3, indicated that the three-factor model, with crisis responsibility, employees' perceptions of organizational reputation, and charismatic leadership communication items loading on unique factors, produced the best fit of all alternative models: $\chi^{2}(849, N=383)=1737.59, p<.01 ; \mathrm{CFI}=.94$; NFI $=.88$; $\mathrm{SRMSR}=.028$; and RMSEA $=.053$. All items loaded significantly on their respective factors. The satisfactory factor structure indicated clear discriminant validity of all variables, which allowed us to proceed with model testing. See Table 3 for the CFA summary and Table 4 for the factor loadings.

We tested our hypotheses with structural equation modeling (SEM). Multiple regression and SEM is a stringent, appropriate, and efficient procedure for testing our model (Preacher \& Hayes, 2008) and it allows (1) simultaneous analyses of variables, which minimizes possible biases (e.g., employees' one-sided rating); (2) supports mediation tests; and (3) identifies sources of variance, thus reducing measurement error. 
Table 4. Standardized Factor Loadings of Items Measuring the Three Theoretical Constructs.

Indicator

Factor

Crisis responsibility

The cause of the crisis was something the organization could control.

The cause of the crisis was something the organization could have

controlled.

The cause of the crisis is something that is manageable by the

organization.

The blame for the crisis lies in the circumstances, not the organization.

The blame for the crisis lies with the organization. ${ }^{\text {b }}$

Circumstances, not the organization, are responsible for the crisis. ${ }^{b}$

Organization reputation

I have a good feeling about the organization.

I admire and respect the organization.

I trust the organization.

This organization stands behind it products and services.

This organization develops innovative products and services.

This organization offers high-quality products and services.

This organization offers products and services that are good value of $.60^{\text {a }}$ money.

This organization has excellent leadership.

This organization has a clear vision for its future.

This organization recognizes and takes advantage of market opportunities.

This organization is well managed.

This organization looks like a good company to work for.

This organization looks like a company that would have good employees. $\quad .85^{\mathrm{a}}$

This organization support good causes.

This organization is an environmentally responsible company.

This organization maintains a high standard in the way it treats people.

Charismatic leadership communication

The leader has a confident communication style.

Is influential.

Is a good public speaker

The leader uses active language.

The leader listens well.

The leader can empathize with others.

Is genuine.

Is understanding of another's feelings.

The leader is poised.

The leader communicates a sense of involvement with the subject matter. 
Table 4. (continued)

\begin{tabular}{lc} 
Indicator & $\begin{array}{c}\text { Factor } \\
\text { loading }\end{array}$ \\
\hline Can put others at ease. & $.72^{\mathrm{a}}$ \\
The leader is enthusiastic. & $.78^{\mathrm{a}}$ \\
The leader uses powerful language. & $.74^{\mathrm{a}}$ \\
The leader is persuasive. & $.80 \mathrm{a}$ \\
The leader is goal oriented. & $.84^{\mathrm{a}}$ \\
The leader is motivational. & $.84^{\mathrm{a}}$ \\
The leader has definite ideas. & $.85^{\mathrm{a}}$ \\
The leader is likely to achieve the goals that he or she sets out to & $.83^{\mathrm{a}}$ \\
accomplish. & $.84^{\mathrm{a}}$ \\
The leader communicates well both verbally and nonverbally. & $.82^{\mathrm{a}}$ \\
The leader is task oriented. & $.83^{\mathrm{a}}$ \\
The leader asks others to share opinion. &
\end{tabular}

alndicates a loading significant at $p<.01$. bltems have been deleted due to low factor loading.

Table 5. Relationship Between Crisis Responsibility (CRISIS), Charismatic Leadership Communication (CHARISMA) and Employees' Perceptions of Organization Reputation (REPUTATION).

\begin{tabular}{lclccr}
\hline & & & $\beta$ & $S E$ & \multicolumn{1}{c}{$t$} \\
\hline REPUTATION & $\leftarrow$ & CRISIS & $.20 I^{*}$ & 0.062 & 3.235 \\
CHARISMA & $\leftarrow$ & CRISIS & $.303^{*}$ & 0.075 & 4.032 \\
REPUTATION & $\leftarrow$ & CHARISMA & $.529 *$ & 0.044 & 11.900 \\
\hline
\end{tabular}

$*_{p}<.01$.

\section{Hypothesis Testing: Structure Equation Modeling}

The result in Table 5 below indicated that a significant relationship between crisis responsibility and perceived organization reputation $(\beta=.201, t=3.232, p<.01)$. This finding shows that while it is statistically significant, the association between the two constructs is moderate to slight, almost negligible (Hair, Money, Samouel, \& Page, 2007). This finding suggests that the attribution of crisis responsibility is directly associated with perceived organization reputation. Thus, Hypothesis 1 was supported. The result also showed that the attribution of crisis responsibility was positively and significantly related to the demonstration of leader's charismatic leadership communication $(\beta=.303, t=4.032, p<.01)$. The result implies that the greater the attribution of crisis responsibility, the stronger the demonstration of charismatic leadership communication by public organization leaders. The strength of the relationship is moderate to minimal. Therefore, Hypothesis 2 was supported. The result also indicated that demonstration of leader's charismatic leadership communication was positively and significantly related 
to perceived organization reputation $(\beta=.529, t=11.900, p<.01)$. The finding suggests that the stronger the demonstration of charismatic leadership communication by the leaders, the better the perception of a public organization's reputation. Therefore, Hypothesis 3 was supported.

\section{Testing for Mediation}

To verify Hypothesis 4, SEM was employed. Baron and Kenny's (1986) casual steps approach to test mediation based on the charismatic leadership communication construct were applied. As shown in Table 6 the models produce an acceptable fit which is consistent with $\mathrm{Hu}$ and Bentler's (1999) guidelines. Results of the X-Y model (Model 1) shows that crisis responsibility significantly and positively related to reputation $(c=.432, \mathrm{t}=6.567, p<.01) . R^{2}$ for Model 1 was .105 . Results of $\mathrm{X}-\mathrm{M}$ model (Model 2) showed that crisis responsibility was significantly and positively related to charismatic leadership communication $(a=.363, t=5.318, p<.01) . R^{2}$ for Model 2 was .072 . As indicated by Model 3, after we included the crisis charismatic leadership communication in the model $(b=.571, t=13.684, p<.01)$, crisis responsibility remained positively and significantly related to reputation but the regression weight was reduced $\left(c^{\prime}=.242, t=4.223, p<.01\right)$. When crisis responsibility was an independent variable, the indirect effect was significant in the hypothesized model as the outcome, $E\left(a_{j} b_{j}\right)=0.19, p<.01, S E=0.02,95 \%$ confidence interval $(\mathrm{CI})=[.088, .204]$ based on 19 iterations. This indicated that $6.8 \%$ of variance was accounted for employees' perceptions of organizational reputation by charismatic leadership communication. The overall $R^{2}$ of the mediation test was .370 . This result demonstrated that (a) crisis responsibility was related to organizational reputation and (b) charismatic leadership communication partially mediated the relationship between crisis responsibility and reputation. Thus, Hypothesis 4 was supported.

\section{Discussion}

We proposed a structural model in which charismatic leadership communication partially mediated crisis responsibility and perceived organizational reputation. Our findings offer an empirically validated conceptual framework of crisis communication and reputation that includes three variables: crisis responsibility, charismatic leadership communication, and perceived organizational reputation. A somewhat surprising finding is that employees' perceptions of their organization reputation are positively related to the attribution they made of crisis responsibility. This aligns with Coombs and Holladay's (2006) argument that a strong reputation could be regarded as "reputational capital," which can create a halo effect that protects an organization during a crisis. The result reveals that employees' positive perceptions may be due to the fact that they perceived the crisis as something that is manageable and could be controlled by the organization.

The positive direction of the relationship between crisis responsibility and organizational reputation indicates that if a crisis were managed successfully organizational 
Table 6. Structural Equation Modeling Results of Charismatic Leadership Communication as a Mediator.

\section{Model}

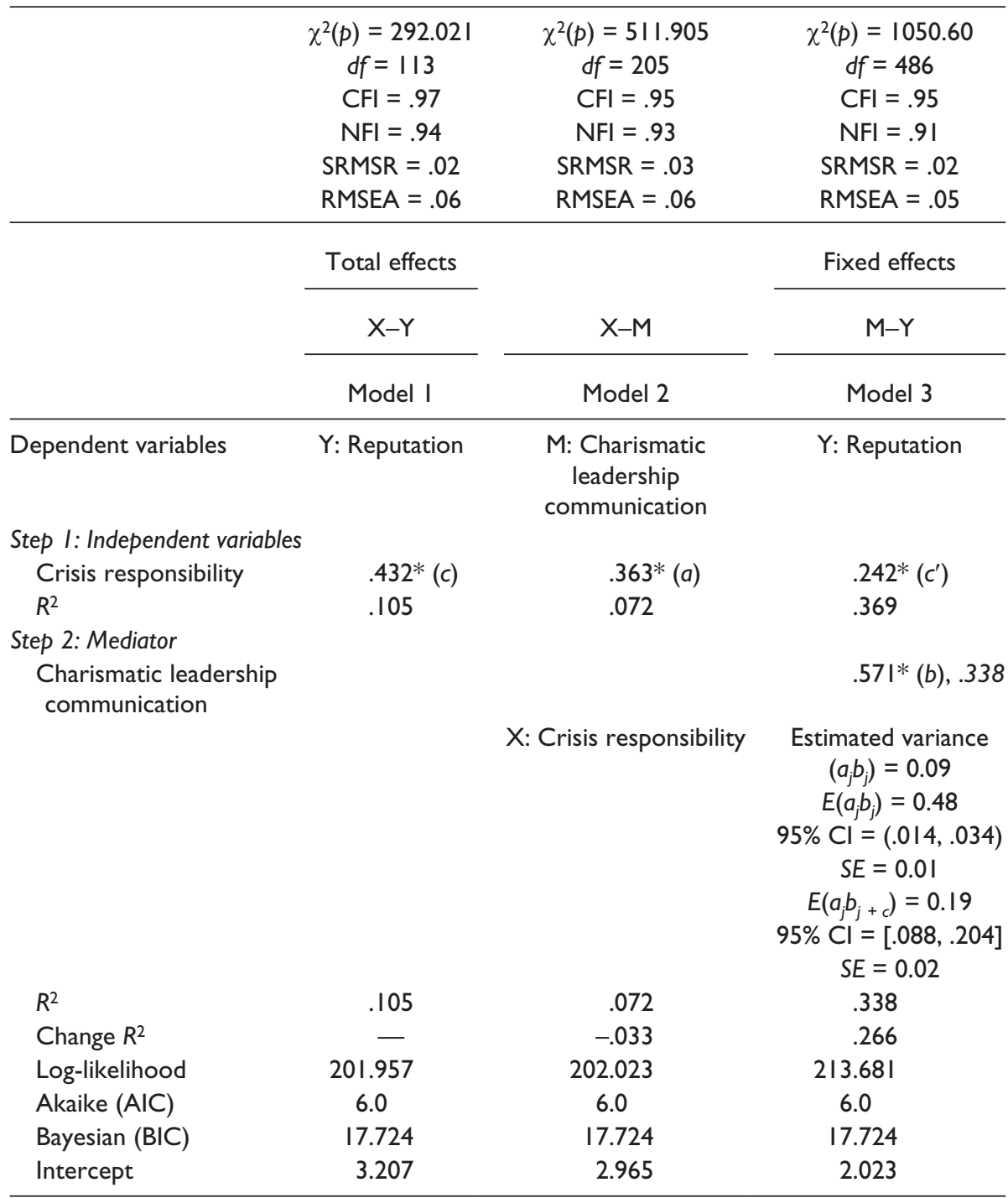

Note. NFI = normed fit index; CFI = comparative fit index; SRMSR = standardized root mean square residual; $\mathrm{RMSEA}=$ root mean square of approximation; $\mathrm{Cl}=$ confidence interval; $\mathrm{AIC}=\mathrm{Akaike}$ information criterion; $\mathrm{BIC}=$ Bayesian information criterion.

$*_{\rho}<.01$

reputation would be secured. Crisis responsibility as the predictor in the study indicates that employees view circumstances, not the organization, as being responsible 
for the crises. As Marconi (2002) put it, "having a bad reputation does not necessarily mean that the organization is at fault; it means a widespread perception exists that the organization is guilty" (p. 114). Thus, internal perceptions suggest that employees know the organization better than do outsiders. As the internal stakeholders, employees are often able to recognize whether the organization is at fault or is being victimized and discredited by another party such as a special-interest group (Marconi, 2002).

Linking to the contextual crises selected for this study, the conclusion can be made that employees feel that an incident involving their organization, close media scrutiny, and political controversy were all manageable and did not perceive their organization's reputation as being tarnished by the crises. A more likely explanation is that the causal relationship is reversed. That is, when organizations face greater attribution for a crisis, they are more likely to be concerned more about their reputation. This situation leaves unanswered a vital question for future studies, which is assessing the direction of the causal relationship.

\section{The Central Role of Charismatic Leadership Communication in the Organizational Reputation Processes}

At the macro level, the mediating effects of perceived charismatic leadership communication on organizational reputation clearly support the notion that communication preserves and protects an organization's valuable reputation (Coombs, 2004). In this study, employees who perceived a stronger demonstration of charismatic leadership communication by their leaders exhibited a more favorable evaluation of their organization's reputation (Men \& Stacks, 2013).

Perceived charismatic leadership communication dimensions such as task-oriented communication, empathy, and enthusiasm are found to directly influence perceived organizational reputation in our model. The findings indicate that the impact of crisis responsibility on organizational reputation varied according to the perception of charismatic leadership communication. In the context of organizational reputation, our findings also show that the crisis leader's ability to communicate charismatically shaped the way in which employees perceive organizational reputation. The demonstration of charismatic leadership communication while assuming the responsibility for the organization during a crisis (Littlefield \& Quennette, 2007) influences stakeholders' favorable perceptions toward the organization's reputation (McDonald, Sparks, \& Glendon, 2010).

\section{Contribution to the Crisis and Organizational Reputation}

Most previous research of charismatic leadership was investigated from managerial aspects of leadership that revolved around noninterpersonal activities such as planning, organizing, decision making, problem solving, and controlling (de Vries et al., 2010; Levine, 2008; McCartney \& Campbell, 2006). In this study, we accounted for charismatic leadership communication by measuring communication perspectives in 
terms of a leader's task-oriented communication, enthusiasm, and empathy. The findings suggest that the three dimensions of charismatic leadership communication are directly influenced by the relationship between crisis responsibility and organizational reputation. These findings contribute to reputation literature in several ways.

First, our result shows that public-sector employees in Malaysia perceived charismatic leaders differently than employees in the West in terms of leadership communication behaviors. Respondents in this study perceived that the leaders who they characterized as charismatic demonstrated traits such as "always be a good public speaker, use(s) active language, uses powerful language, and is task oriented." Previous study in the West indicated that charismatic leaders were perceived as poised, skillful speakers, goal-oriented, and, comfortable when engaged in public speaking.

However, both Western and Asian respondents exhibited some similarity about the traits they perceived their charismatic leaders as demonstrating, including the ability to empathize with others, being enthusiastic, having definite ideas, and asking others to their share opinions. However, the differences and similarities of leaders' charismatic communication traits were evaluated in two different situations and purposes; previous studies identified communication behaviors to define charismatic communication, while the present study assessed charismatic communication demonstrated by leaders while managing a crisis.

Second, the findings of this study validated the notions Coombs (2004, 2007, 2012), Liu et al. (2012), and Stephens, Malone, and Bailey (2005) brought forward that organizations use communication to shape perceptions toward crisis responsibility by framing crisis news through the practice of charismatic leadership communication. Our findings also indicate that a leader who demonstrates communication behaviors such as being positive, understanding the victim's feelings and expressing genuine concerns, and being able to empathize with the victims during crisis influences perceptions of organizational reputation.

Third, in addressing the issues of the stakeholders involved, a leader's use of appropriate body language often indicate positive communicative, thus helping ease a difficult situation. This finding supports the conclusions of Holladay and Coombs (1994); Coombs and Holladay (2001); and Levine et al. (2010) that nonverbal communication of a charismatic leader is important for bringing forth the emotional side of that leader during a crisis.

Finally, our structural mediation model approach suggests that the traditional leadership approach focusing solely on managerial charismatic leadership may be inadequate. Rather, the effectiveness of a leader is likely the result of his or her communication ability through task-oriented communication, enthusiasm, and empathy during a crisis, which complements the managerial communication aspect of leadership. Furthermore, for the whole of internal stakeholders in an organization, charismatic leadership communication perhaps is the most important antecedent to organizational reputation.

Although our charismatic leadership communication style-based model is derived from relevant findings based on predominantly Western research, we empirically validated the model with a Malaysian sample. Thus, communication centeredness and 
SCCT principles exhibited some degree of cross-cultural validity. Nonetheless, our mediation model of perceived charismatic leadership communication likely belies the richness of work culture in Malaysian organizations in which coordination, mutual help, work task integration, and concerted pursuit of organization goals are the norm (Bakar \& Sheer, 2013).

\section{Practical Implications}

The main practical implications are related to the central role of charismatic leadership communication in the organizational reputation processes. The dynamic nature of charismatic leadership communication can change reputational outcomes directly and change the impact level of crisis responsibility on organizational reputation. We suggest that during a crisis a leader should initiate and communicate with internal stakeholders using critical interpersonal aspects of leadership communication, both verbal and nonverbally, to strengthen organizational reputation. More importantly, our finding that charismatic leadership communication contributed to organizational reputation explicitly brought charismatic leadership communication to the forefront of organizational reputation management.

\section{Limitations and Future Research}

The cross-sectional nature of the data presented here does not eliminate the possibility that causal relationships described in the model could be reversed. First, although our additional tests helped us rule out the reversal causation statistically, experimental and longitudinal research is needed to establish true causation. Second, charismatic leadership communication was measured via employee perceptions that may deviate from what actually happened. Future research could record and content analyze actual interactions among top management people. Third, the charismatic leadership communication measures (Levine et al., 2010) adopted in this study treated the construct largely as overall leader communication style. Alternative measures can be developed to examine a collection of specific leader communication behaviors. Fourth, our sample was restricted to only Malaysian respondents. Samples with respondents from other countries should be considered to enhance the generalizability of the model. Finally, this study does not measure environmental factors such as organizational culture and climate that may affect the way in which Malaysians perceived organizational reputation compared with Westerners.

This study examined only organizational reputation, and other outcomes may be equally relevant to our model. Future research should probe further as to whether charismatic leadership communication, too, mediates the relationships between crisis responsibility and other possible key organizational reputation outcomes such as media coverage and stakeholder's loyalty. Finally, for management training purposes, future research could profitably investigate specific communication acts and behaviors that managers and organization members consider during a crisis. Through charismatic leadership communication training, organizational outcomes could be enhanced. 


\section{Declaration of Conflicting Interests}

The author(s) declared no potential conflicts of interest with respect to the research, authorship, and/or publication of this article.

\section{Funding}

The author(s) received no financial support for the research, authorship, and/or publication of this article.

\section{References}

Abd-El-Salam, E. M., Shawky, A. Y., El-Nahas, T., \& Nawar, Y. S. (2013). The relationship among job satisfaction, motivation, leadership, communication, and psychological empowerment: An Egyptian case study. SAM Advanced Management Journal, 78, 33-50.

Antonakis, J., Fenley, M., \& Liechti, S. (2011). Can charisma be taught? Tests of two interventions. Academy of Management Learning \& Education, 10, 374-396.

Bakar, H. A., Dilbeck, K. E., \& McCroskey, J. C. (2010). Mediating role of supervisory communication practices on relations between leader-member exchange and perceived employee commitment to workgroup. Communication Monographs, 77, 637-656.

Bakar, H. A., \& Sheer, V. C. (2013). The mediating role of perceived cooperative communication in the relationship between interpersonal exchange relationships and perceived group cohesion. Management Communication Quarterly, 27, 443-465.

Baron, R. M., \& Kenny, D. A. (1986). The moderator-mediator variable distinction in social psychological research: Conceptual, strategic, and statistical considerations. Journal of Personality and Social Psychology, 51, 1173-1182.

Bligh, M. C., Kohles, J. C., \& Meindl, J. R. (2004). Charisma under crisis: Presidential leadership, rhetoric, and media responses before and after the September 11th terrorist attacks. Leadership Quarterly, 15, 211-239.

Bligh, M. C., Kohles, J. C., \& Pillai, R. (2005). Crisis and charisma in the California recall election. Leadership, 1, 323-352.

Chetthamrongchai, P. (2010). Revalidating two measures of reputation in Thailand. Corporate Reputation Review, 13, 209-219.

Claeys, A.-S., Cauberghe, V., \& Vyncke, P. (2010). Restoring reputations in times of crisis: An experimental study of the situational crisis communication theory and the moderating effects of locus of control. Public Relations Review, 36, 256-262.

Coldwell, D. A. L., Joosub, T., \& Papageorgiou, E. (2012). Responsible leadership in organizational crises: An analysis of the effects of public perceptions of selected SA business organizations' reputations. Journal of Business Ethics, 109, 133-144.

Conger, J. A., Kanungo, R. N., \& Menon, S. T. (2000). Charismatic leadership and follower effects. Journal of Organizational Behavior, 21, 747-767.

Coombs, W. T. (2004). Impact of past crisis on current crisis communications: Insights from situational crisis communication theory. Journal of Business Communication, 41, 265289.

Coombs, W. T. (2007). Protecting organization reputations during a crisis: The development and application of situational crisis communication theory. Corporate Reputation Review, $10,1-14$.

Coombs, W. T. (2012). Ongoing crisis communication: Planning, managing and responding. Thousand Oaks, CA: Sage. 
Coombs, W. T., \& Holladay, S. J. (2001). An extended examination of the crisis situation: A fusion of the relational management and symbolic approaches. Journal of Public Relation Research, 13, 321-340.

Coombs, W. T., \& Holladay, S. J. (2002). Helping crisis managers protect reputational assets: Initial test of the situational crisis communication theory. Management Communication Quarterly, 16, 165-186.

Coombs, W. T., \& Holladay, S. J. (2006). Unpacking the halo effect: Reputation and crisis management. Journal of Communication Management, 10, 123-137.

Coombs, W. T., \& Holladay, S. J. (2010). PR strategy and application: Managing influence. Chichester, England: Wiley-Blackwell.

Davis, K. M. (2012). Charisma under crisis revisited: Presidential leadership, perceived leader effectiveness, and contextual influences. Leadership Quarterly, 23, 918-933.

de Vries, R. E., Bakker-Pieper, A., \& Oostenveld, W. (2010). Leadership = communication? The relations of leaders' communication styles with leadership styles, knowledge sharing and leadership outcomes. Journal of Business \& Psychology, 25, 367-380.

Delgado-Garcia, J. B., De Quevedo-Puente, E., \& De La Fuente-Sabate, J. M. (2010). The impact of ownership structure on corporate reputation: Evidence from Spain. Corporate Governance: An International Review, 18, 540-556.

Fombrun, C. J. (1996). Reputation: Realizing value from the corporate image. Cambridge, MA: Harvard Business School Press.

Fombrun, C. J., \& Van Riel, C. B. M. (2004). Fame \& fortune: How successful companies build winning reputations. Upper Saddle Hill, NJ: Prentice Hall.

Frese, M., Beimel, S., \& Schoenborn, S. (2003). Action training for charismatic leadership: Two evaluations of studies of a commercial training module on inspirational communication of a vision. Personnel Psychology, 56, 671-697.

George, B., Sims, P., McLean, A. N., \& Mayer, D. (2007). Discovering your authentic leadership. Harvard Business Review, 85, 129-138.

Graen, G. B., \& Uhl-Bien, M. (1995). Relationship-based approach to leadership: Development of leader-member exchange (LMX) theory of leadership over 25 years: Applying a multilevel multi-domain perspective. Leadership Quarterly, 6, 219-247.

Grunwald, G., \& Hempelmann, B. (2010). Impacts of reputation for quality on perceptions of company responsibility and product-related dangers in times of product-recall and public complaints crises: Results from an empirical investigation. Corporate Reputation Review, 13, 264-283.

Hair, J. F., Jr., Money, A. H., Samouel, P., \& Page, M. (2007). Research methods for business. New York, NY: John Wiley.

Hale, J. E., Dulek, R. E., \& Hale, D. P. (2005). Crisis response communication challenges. Journal of Business Communication, 42, 112-134.

Halverson, S. K., Holladay, C. L., Kazama, S. M., \& Quiñones, M. A. (2004). Self-sacrificial behavior in crisis situations: The competing roles of behavioral and situational factors. Leadership Quarterly, 15, 263-275.

Hamdi, S., \& Rajablu, M. (2012). Effect of supervisor-subordinate communication and leadership style on organizational commitment of nurses in health care setting. International Journal of Business \& Management, 7, 7-18.

Hector, C. (2011, August 20). Teoh Beng Hock RCI-Was it an investigation or a justification exercise? Retrieved from http://charleshector.blogspot.com

Helm, S. V., \& Tolsdorf, J. (2009, February). The impact of corporate crises on customer loyalty: Does corporate reputation cushion the fall? Paper presented at the AMA Winter Educators' Conference, Tampa, FL. 
Holladay, S. J., \& Coombs, W. T. (1994). Speaking of visions and visions being spoken: An exploration of the effects of content and delivery on perceptions of leader charisma. Management Communication Quarterly, 8, 165-189.

Hooijberg, R., \& Choi, J. (2001). The impact of organizational characteristics on leadership effectiveness models: An examination of leadership in a private and a public sector organization. Administration \& Society, 33, 403-431.

Hu, L., \& Bentler, P. M. (1999). Cutoff criteria for fit indexes in covariance structure analysis: Conventional criteria versus new alternatives. Structural Equation Modeling, 6, 1-55.

Jin, C.-H., \& Yeo, H.-C. (2011). Satisfaction, corporate credibility, CEO reputation and leadership effects on public relationships. Journal of Targeting, Measurement and Analysis for Marketing, 19, 127-140.

Kakavogianni, D. (2009). Charismatic leadership and its emergence under crisis conditions: A case study from the airline industry (The University of York Working Paper). Retrieved from http://eprints.whiterose.ac.uk

King, G. (2002). Crisis management and team effectiveness: A closer examination. Journal of Business Ethics, 41, 235-249.

Lager, J. M. (2010). Governments demand compliance, ethics demands leadership. Journal of Public Affairs, 10, 216-224.

Levine, K. (2008, May). Communicating charisma: Developing the Charismatic Leadership Communication Scale. Paper presented at the International Communication Association, Montreal, Quebec Canada.

Levine, K. J., Muenchen, R. A., \& Brooks, A. M. (2010). Measuring transformational and charismatic leadership: Why isn't charisma measured? Communication Monographs, 77, 576-591.

Littlefield, R. S., \& Quennette, A. M. (2007). Crisis leadership and hurricane Katrina: The portrayal of authority by the media in natural disasters. Journal of Applied Communication Research, 35, 26-47.

Liu, B. F., Horsley, J. S., \& Yang, K. (2012). Overcoming negative media coverage: Does government communication matter? Journal of Public Administration Research and Theory, 22, 597-621.

Lucero, M., Tan, T. K., \& Pang, A. (2009). Crisis leadership: When should the CEO step up? Corporate Communications: An International Journal, 14, 234-248.

Madlock, P. (2008). The link between leadership style, communicator competence, and employee satisfaction. Journal of Business Communication, 45, 61-78.

Maor, M., Gilad, S., \& Ben-Nun Bloom, P. (2013). Organizational reputation, regulatory talk, and strategic silence. Journal of Public Administration Research \& Theory, 23, 581-608.

Marconi, J. (2002). Reputation marketing: Building and sustaining your organization's greatest asset. New York, NY: McGraw-Hill.

McCartney, W. W., \& Campbell, C. R. (2006). Leadership, management, and derailment: A model of individual success and failure. Leadership \& Organization Development Journal, 27, 190-202.

McDonald, L. M., Sparks, B., \& Glendon, A. I. (2010). Stakeholder reactions to company crisis communication and causes. Public Relations Review, 36, 263-271.

Men, L. R., \& Stacks, D. W. (2013). The impact of leadership style and employee empowerment on perceived organizational reputation. Journal of Communication Management, 17, 171-192.

Meng, J., \& Berger, B. (2013). An integrated model of excellent leadership in public relations: Dimensions, measurement, and validation. Journal of Public Relations Research, 25, 141-167. 
Ota, H., McCann, R. M., \& Honeycutt, J. M. (2012). Inter-Asian variability in intergenerational communication. Human Communication Research, 38, 172-198.

O’Toole, L. J. J., \& Meier, K. J. (2009). The human side of public organizations: Contributions to organizational performance. American Review of Public Administration, 39, 499-518.

Pillai, R. (1996). Crisis and the emergence of charismatic leadership in groups: An experimental investigation. Journal of Applied Social Psychology, 26, 543-562.

Pillai, R., \& Meindl, J. R. (1998). Context and charisma: A "meso" level examination of the relationship of organic structure, collectivism, and crisis to charismatic leadership. Journal of Management, 24, 643-671.

Preacher, K. J., \& Hayes, A. F. (2008). Asymptotic and resampling strategies for assessing and comparing indirect effects in multiple mediator models. Behavior Research Methods, 40, 879-891.

Reduan, H. (2014, September 5). Teoh Beng Hock open verdict reversed. The New Straits Times, p. 1.

Renshon, S. A. (1995). The Clinton presidency: Campaigning, governing and psychology of leadership. Boulder, CO: Westview Press.

Schoenberg, A. (2005). Do crisis plan matter? A new perspective on leading during a crisis. Public Relations Quarterly, 50, 2-6.

Seibold, D. R., Hollingshead, A. B., \& Yoon, K. (2014). Embedded teams and embedding organizations. Thousand Oaks, CA: Sage.

Sisco, H. F. (2012). Nonprofit in crisis: An examination of the applicability of situational crisis communication theory. Journal of Public Relations Research, 24, 1-17.

Stephens, K. K., Malone, P. C., \& Bailey, C. M. (2005). Communicating with stakeholders during a crisis. Journal of Business Communication, 42, 390-419.

Tan, Y. L. (2014, September 9). Cops urged to conduct criminal investigation into Teoh Beng Hock's death. The Star, p. 1.

Tucker, L., \& Melewar, T. C. (2005). Corporate reputation and crisis management: The threat and manageability of anti-corporatism. Corporate Reputation Review, 7, 377-387.

Turk, J. V., Jin, Y., Stewart, S., Kim, J., \& Hipple, J. R. (2012). Examining the interplay of an organization's prior reputation, CEO's visibility, and immediate response to a crisis. Public Relations Review, 38, 574-583.

Van der Jagt, R. (2005). Senior business executives see communication and reputation as a crucial part of their leadership role. Corporate Reputation Review, 8, 179-186.

Vigoda-Gadot, E., Zalmanovitch, Y., \& Belonogov, A. (2012). Public servants' trust in citizens: An extension of theory and an empirical examination with structural equation modeling (SEM). Public Organization Review, 12, 383-399.

Wæraas, A., \& Byrkjeflot, H. (2012). Public sector organizations and reputation management: Five problems. International Public Management Journal, 15, 186-206.

Walter, F., \& Bruch, H. (2009). An affective events model of charismatic leadership behavior: A review, theoretical integration, and research agenda. Journal of Management, 35, 1428-1452.

Wang, D.-S., \& Hsieh, C.-C. (2013). The effect of authentic leadership on employee trust and employment engagement. Social Behavior and Personality, 41, 613-624.

Watson, T. (2007). Reputation and ethical behaviour in a crisis: Predicting survival. Journal of Communication Management, 11, 371-384.

Weber, M., Erickson, S. L., \& Stone, M. (2011). Corporate reputation management: Citibank's use of image restoration strategies during the U.S. banking crisis. Journal of Organizational Culture, Communications \& Conflict, 15, 35-55. 
Wester, M. (2009). Cause and consequences of crises: How perception can influence communication. Journal of Contingencies and Crisis Management, 17, 118-125.

\section{Author Biographies}

Jamilah Jamal is a PhD candidate and an academic staff in the Department of Communication, School of Multimedia Technology and Communication, Universiti Utara Malaysia, Malaysia. Her area of interests are in crisis communication, leadership communication and reputation management.

Hassan Abu Bakar is an Associate Professor in the Department of Communication, School of Multimedia Technology and Communication, and Othman Yeop Abdullah Graduate School of Business, Universiti Utara Malaysia, Malaysia. His main research interests are in dyadic communication in workplace, leadership style, organizational communication and cultural context. 